\title{
Improving biodegradability of polyvinyl alcohol/starch blend films for packaging applications
}

\author{
Negim E.S.M. ${ }^{1,2}$ *, Rakhmetullayeva R.K. ${ }^{3}$, Yeligbayeva G.Zh. ${ }^{4}$, Urkimbaeva P.I. ${ }^{3}$, \\ Primzharova S.T. ${ }^{3}$, Kaldybekov D.B. ${ }^{4}$, Khatib J.M. ${ }^{1}$, Mun G. A. ${ }^{3}$, Craig W. ${ }^{1}$ \\ ${ }^{I}$ Faculty of Sciences and Engineering, University of Wolverhampton, Wulfruna Street, \\ Wolverhampton, West Midlands, WV1 1LY, UK \\ ${ }^{2}$ Polymers and Pigments Department, National Research Centre, Dokki, Giza 12622, Egypt \\ ${ }^{3}$ Department of Organic Substances, Chemistry and Technology, Natural Compounds and Polymers, \\ Al-Faraby Kazakh National University, 050038 Almaty, Kazakhstan \\ ${ }^{4}$ K.I. Satpaev Kazakh National Technical University 22, Satpaev avenue, Almaty, 050013, Kazakhstan \\ *Corresponding author E-mail: elashmawi5@yahoo.com
}

Copyright $\odot 2014$ Negim E.S.M et al. This is an open access article distributed under the Creative Commons Attribution License, which permits unrestricted use, distribution, and reproduction in any medium, provided the original work is properly cited.

\begin{abstract}
Polyvinyl alcohol (PVA) was blended with starch (S) in presence of glacial acetic acid as crosslinking agent. The effect of blend ratio and molecular weight of PVA on the physical, thermal and mechanical properties of PVA/S blends were investigated using various techniques such as DSC, TGA, SEM, tensile strength, and solubility tests. Furthermore, biodegradability of the blend films was also studied. In addition, FTIR spectroscopy was used to check the hydrogen bonding interaction between PVA and $\mathrm{S}$ in the blends. The obtained results showed that the physico-mechanical properties are strongly dependent on the molecular weight and PVA content in PVA/S blends. DSC and SEM analyses of PVA/S blend showed a single glass transition temperature indicating the formation of completely miscible blends with a single phase due to the formation of hydrogen bonds between the hydroxyl groups of PVA and starch. In addition, PVA/S blend films exhibited good mechanical properties, thermal stability as compared with the pure PVA. More interestingly, the results showed enhancement in biodegradability of PVA/S blend films and particularly in moist soil, which can be exploited for manufacturing of biodegradable and environmentally friendly packaging materials at low cost.
\end{abstract}

\section{Introduction}

Recently, the use of biodegradable polymers for packaging materials offers an alternative and partial solution to the problem of accumulation of solid waste composed of synthetic inert polymers [1]. Starch, as an abundant and inexpensive raw material, has been applied in the field of biomaterials. However, packaging films composed entirely of starch lack the strength and rigidity to withstand the stresses to which many packaging materials are subjected [2].

In the last decades, polymer blends have attracted great attention due to the capability for providing new materials with extended useful properties beyond the range that can be obtained from single polymer equivalents. Accordingly, various polymer blends have been extensively studied to for use in various industrial and technological applications. However, in some cases blending of polymers may not produce desirable properties due to the poor miscibility or incompatibility between the blended polymers which leads to rough phase structure, poor adhesion at the interface, and therefore poor mechanical properties. Generally, compatibility arises from thermodynamic interaction between the blend constituents, which is a function of their physical properties and chemical structure [3], [4]. Physical or chemical crosslinking is therefore necessary to improve the structural integrity of the polymer blends [5].

Starch is a naturally abundant and biodegradable polymer that consists of D-glucose as a building unit containing hydroxyl (-OH) groups, which are directed outside the ring [6]. Lu et al., [7] reported that starch is biodegradable, cheap and can be easily modified physically or chemically to improve its properties via blending, functionalization or via graft 
copolymerization [8]. When starch and hydroxyl containing polymers such as poly(vinyl alcohol) (PVA) are blended, these highly polar polymers rich with hydroxyl groups tend to form intermolecular and intramolecular hydrogen bonds, which improve stability and integrity of starch/PVA blends. However, the obtained PVA/starch polymer blends are usually hard and brittle. Therefore, the addition of plasticizers such as glycerol, sorbitol and/or urea can overcome the brittleness problem through the formation of a more stable and flexible hydrogen bonding [5], [9].

PVA is a water-soluble and biodegradable polymer [10], and has excellent mechanical properties, in addition to its compatibility with starch. Thus, PVA/starch blend is assumed to be biodegradable since both its components are biodegradable in various microbial environments. Recently, modification of chemical and physical properties of PVA/ starch blends is of great research interest to modify its properties in order to achieve ultimate novel characteristics to be used in manufacturing of biodegradable packaging materials. For instance, it was reported that the tensile strength, elongation at break, and transparency of the PVA/starch blend composites decreased by increasing the starch content in the blend [11]. In order to resolve this problem, Jianga et al., [12] have modified PVA/starch blend films by incorporation of plasticized $\mathrm{CaCl}_{2}$, which makes the blend softer and ductile (i.e. it has lower tensile strength and higher elongations at break) as compared with the pure PVA/starch film. In addition, the water content of PVA/starch films would increase with the addition of $\mathrm{CaCl}_{2}$. The results indicated that $\mathrm{CaCl}_{2}$ could interact with starch and PVA molecules and then effectively destroy the crystals of starch and PVA.

Xuegang et al., [13] have prepared modified (gelatinized) PVA/starch blend films by introducing glycerol/urea as additives, using a solution casting method. It was found that themelting temperature $\left(T_{m}\right)$ of the gelatinized PVA/starch blends was higher than that of the ungelatinized starch/PVA blends. Moreover, the blend films containing $16.8 \mathrm{wt} \%$ of glycerol or urea exhibited a drastic decrease in $T_{m}$. These thermal behaviors could be attributed to the different hydrogen bonding interaction characteristics between starch and PVA at different conditions. Lee et al., [14] studied the thermal degradation of PVA/cassava starch (CSV) blends using thermal gravimetric analysis (TGA). It was noticed that the blending of PVA with CSV lead to the enhancement in thermal stability of the blend, and particularly at 40-50 wt. $\%$ of PVA.

Authors [15] developed a new method to modify surface the thermoplastic starch (TPS)/PVA blend films by crosslinking through soaking in a photosensitizer aqueous solution. The obtained results showed that the surface modification considerably reduced the surface hydrophilic character of the TPS/PVA films, which led to enhancement in the water resistance of the prepared blend films. Furthermore, an increase in tensile strength and Young's modulus and a decrease in elongation at break of the films were also noticed. The same behavior was reported by authors [16], when they described a method which could be used for post-treating TPS/PVA based products by crosslinking through soaking the blend films in sodium carbonate aqueous solution and sodium hexametaphosphate aqueous solution in a sequential manner, and then followed by heating.

Recently, authors [17], [18] have found that the use of organic acids, such as citric, maleic and/or tartaric acids could enhance the compatibility between the polymeric phases, producing more homogeneous blends with better mechanical properties. In this regard, tartaric acid was also evaluated by Yunet et al., [19], resulting in PVA/starch blend films with improved properties. Rui et al., [20] have also studied the effect of citric acid (CA) percentages on the structure and physical properties of the PVA/starch blend films plasticized with glycerol. It was found that the addition of CA to such blends led to the formation of crosslinks between PVA and starch via strong hydrogen bonds, which result in enhancement of the thermal stability of the PVA/starch blend films. Furthermore, the water absorbance of the blend films decreased from $33 \%$ to $20 \%$ as the CA percentage increased from 5 to $30 \mathrm{wt} \%$. Upon addition of CA at $5 \mathrm{wt} \%$, the tensile strength of the sample increased from 39 to $48 \mathrm{MPa}$. However, further addition of CA ( $>5$ to $30 \mathrm{wt} \%$ ) led to a significant decrease in the tensile strength from 48 to $42 \mathrm{MPa}$, while the elongation at break increased from $102 \%$ to $208 \%$.

This article describes the blend of PVA with starch in the presence of glacial acetic acid as a crosslinking agent. The influence of blend ratio and molecular weight $\left(31 \times 10^{3}\right.$ and $\left.205 \times 10^{3} \mathrm{~g} / \mathrm{mole}\right)$ of PVA on physical and mechanical properties of PVA/S blends was studied. Biodegradability of the prepared PVA/S blend films was also investigated.

\section{Experimental}

\subsection{Materials}

Poly (vinyl alcohol) (PVA) with two different molecular weights ( $\mathrm{Mw}=31 \times 10^{3}$ and 205x 10 $\left.\mathrm{g} / \mathrm{mol}\right)$ was supplied by Fluka, Switzerland. Corn starch (S) was obtained from Changchun Jincheng Corn Development Co. Ltd., Da Cheng Group (China). Glacial acetic acid was purchased from Merck (Germany). All these chemicals were of pure grade and used as received.

\subsection{Methods}

\subsubsection{Preparation of PVA/S blends}


PVA/S blends with different blend ratios (M1=70:30, M2=80:20, M3=90:10 and M4=95:05 w/w) were prepared. Briefly, PVA was first dissolved in distilled water in a three necked flask under continuous mechanical stirring and heating in a water bath at $40{ }^{\circ} \mathrm{C} \pm 3{ }^{\circ} \mathrm{C}$ for $20 \mathrm{~min}$ till complete dissolution of PVA, and then, the flask was sealed with a septum stopper. The prepared PVA solution was flushed with Nitrogen gas, which was introduced through a hypodermic needle, and another needle was introduced inside the stopper for the outlet of Nitrogen gas. Then, the corn starch (S) solution was added drop wisely through a separating funnel connected to the three necked flask, and the mixture was heated at $90{ }^{\circ} \mathrm{C} \pm 3{ }^{\circ} \mathrm{C}$ for another $20 \mathrm{~min}$. Glacial acetic acid was injected through a hypodermic needle during preparation in order to control the $\mathrm{pH}$ of the solution at $3 \pm 1$. Nitrogen gas flushing was continued for a further $30 \mathrm{~min}$ and then stopped, and the needles were removed from the stopper and then the flask was sealed with a Teflon tape. The temperature of the reaction was maintained at $90^{\circ} \mathrm{C} \pm 3{ }^{\circ} \mathrm{C}$ for another 3 hours. The prepared PVA/S blend solutions were homogeneous and stable for more than 6 months at room temperature.

\subsubsection{Preparation of PVA/S films}

PVA/S blend films were prepared by casting their aqueous solutions onto flat glass surfaces and allowing them to dry at room temperature for 7 days, and then in an aerated oven at $60{ }^{\circ} \mathrm{C}$, for $12 \mathrm{~h}$ to completely eliminate water [21-25]. Then, the films were washed thoroughly with distilled water in order to eliminate the residual glacial acetic acid. Finally, the films were dried and stored in a desiccator at room temperature for further characterization and measurements.

\subsubsection{Testing}

Chemical composition of PVA, S and their blends were verified by FTIR spectra, which were recorded on a Bruker Tensor 37 FTIR spectrometer. The tensile properties of the dry PVA/S blend films were measured by using MTS 10/M tensile testing machine at a crosshead speed of $50 \mathrm{~mm} / \mathrm{min}$. Glass transition temperature $\left(T_{g}\right)$ of samples were measured using differential scanning calorimetry (DSC) (NETZSCH DSC200PC), using aluminum crimped pans under $\mathrm{N}_{2}$ atmosphere at flow rate $20 \mathrm{~mL} \mathrm{~min}{ }^{-1}$. The measurements were carried out between $25^{\circ} \mathrm{C}$ and $210{ }^{\circ} \mathrm{C}$ at a heating rate of $10{ }^{\circ} \mathrm{C} \cdot \mathrm{min}^{-1}$. Thermogravimetric analyses were performed using a Perkin-Elmer TG-7 analyzer. Film samples ranging from 3-7 mg were placed in a platinum sample pan and heated from 25 to $900^{\circ} \mathrm{C}$ under $\mathrm{N}_{2}$ atmosphere at a heating rate of $10^{\circ} \mathrm{C} \cdot \mathrm{min}^{-1}$. During the heating period, the weight loss and temperature difference were recorded as a function of temperature. The microstructure and miscibility of the prepared blends were also investigated by using scanning electron microscopy (SEM) (Carl-Ziess SMT, Oberkochen).

The degree of solubility of the PVA/S blend films samples was carried out by measuring the weight of the films after immersion in either water or in water/ethanol (v/v: 70/30) at different temperatures $\left(20,25,30,37\right.$, and $\left.40{ }^{\circ} \mathrm{C}\right)$ and compared with the weight of the dry films prior to immersion. The degree of solubility of the blend films was determined according to the following formula:

$\%$ Solubility $=\left[\left(\mathrm{m}-\mathrm{m}_{0}\right) / \mathrm{m}\right] \times 100$

Where $\mathrm{m}$ and $\mathrm{m}_{0}$ represent the weight of the films prior and after immersion, respectively.

Biodegradation experiments of PVA/S blend films were carried out in a conventional soil placed in a plastic container. Two types of soils were used, a moist soil and a dry soil taken from the courtyard of the Faculty of Chemistry and Chemical Technology. The biodegradability of polymeric films was examined after burying them in moist and dry soils for 30 days.

\section{Results and discussion}

\subsection{FT-IR spectroscopy}

The reaction between PVA with and S was confirmed by FT-IR spectroscopy, as shown in Fig. 1. In Fig. 1a, the peaks appearing at 2955, 1264 and 668 and $1096 \mathrm{~cm}^{-1}$ is attributed to the $\mathrm{C}-\mathrm{H}$ stretching, $\mathrm{C}-\mathrm{H}$ bending and $\mathrm{C}-\mathrm{O}$ stretching bands of PVA, respectively. The broad absorption peak appearing at $3406 \mathrm{~cm}^{-1}$ is related to the $\mathrm{O}-\mathrm{H}$ stretching frequencies of PVA and water hydroxyl groups. The characteristic carbonyl group $(\mathrm{C}=\mathrm{O})$ band at $1708 \mathrm{~cm}^{-1}$ is related to the residual acetate groups, remaining after the manufacture of PVA from the hydrolysis of polyvinyl acetate [26].

After blending of PVA with S, the prepared PVA/S blend films showed a broad band around $3500-3100 \mathrm{~cm}^{-1}$ which is attributed to the $\mathrm{O}-\mathrm{H}$ stretching. The bands at 1240 and $1082 \mathrm{~cm}^{-1}$ are attributed to the stretching vibration of $\mathrm{C}-\mathrm{O}$ in $\mathrm{C}-\mathrm{O}-\mathrm{H}$ groups, and the band at $1020 \mathrm{~cm}^{-1}$ is related to the $\mathrm{C}-\mathrm{O}$ stretching vibration of $\mathrm{C}-\mathrm{O}-\mathrm{C}$ groups of the glucose unit in starch (Fig. 1, M1-M4). In addition, the characteristic absorption peak of the carbonyl group of acetic acid is observed at $1732 \mathrm{~cm}^{-1}$, and the aliphatic $\mathrm{C}-\mathrm{H}$ stretching vibration band appeared at $2937 \mathrm{~cm}^{-1}$.

Since the films were thoroughly washed with water to remove the unbound acetic acid, the presence of the carbonyl peak confirms the chemical linkages between PVA and starch in the presence of acetic acid, which promotes the interaction between PVA and starch, as previously reported [27]. As shown in Figs. 1, the band around $1425 \mathrm{~cm}^{-1}(\mathrm{C}-\mathrm{H}$ 
stretch) belongs to the spectrum of PVA. On the other hand, the absorption peaks appearing at 1425,1373, and $845 \mathrm{~cm}^{-1}$ are due to the starch only and this is an ideal reference frequency to monitor starch content in the films. As expected and in agreement with previously reported results by other authors [28], [29], PVA/S blend films showed a broad band between 3550 and $3200 \mathrm{~cm}^{-1}$, which is related to the stretching band arising from the intermolecular hydrogen bonds between O-H groups of PVA and starch. The same behavior was reported by authors [30], when they studied FTIR spectroscopy of PVA, which chemically crosslinked with glutaraldehyde.

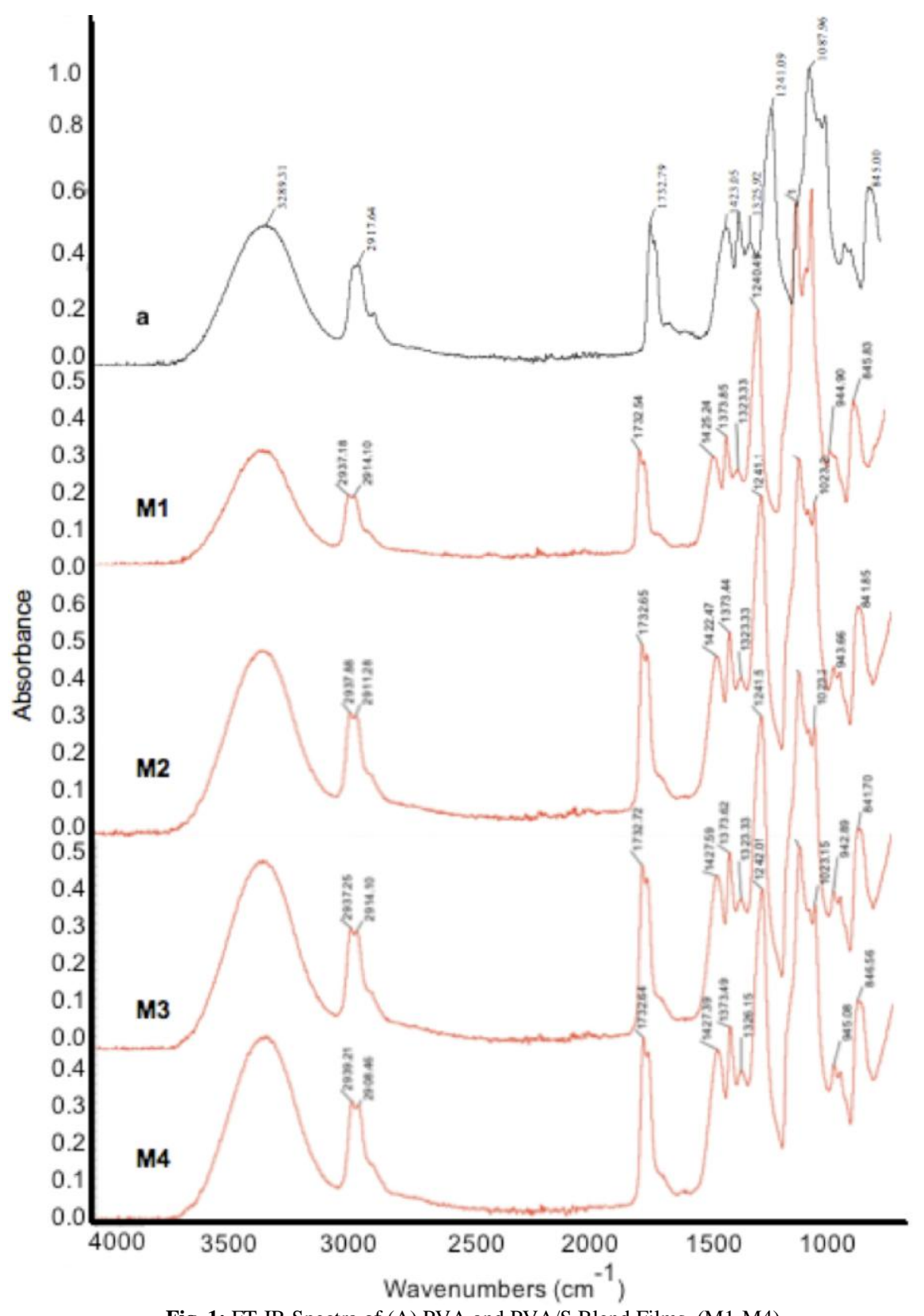

Fig. 1: FT-IR Spectra of (A) PVA and PVA/S Blend Films, (M1-M4).

\subsection{Transparency and appearance of PVA/S blend films}

The effect of PVA content on the transparency and appearance of the PVA/starch blend films was investigated. It was observed that the transparency and flexibility of PVA/S blend films increase by increasing PVA content in the blend. As previously reported [31], [32], the amylose and amylopectin ratio in the starch may affect the properties of starch-based products, forming brittle films due to the extensive interactions between starch chains through hydrogen bonding, electrostatic and hydrophobic interactions. Accordingly, the usual approach to enhance film-forming properties is to add a plasticizer. PVA is considered as a hydrophilic plasticizer that reduces starch chain-to-chain interaction. As a result, the increase of PVA ratio lowers the glass transition temperature of the starch, forming more flexible and soft films. Furthermore, it was found that glacial acetic acid breaks down the amylopectin and changes the structure and properties of the polymer [33]. 


\subsection{Solubility of PVA/S blend films}

The effect of molecular weight and content of PVA on solubility of the PVA/S blend films in either water or ethanol/water solution as a function of time is shown in (Fig. 2 A-D). It is obvious that the time of solubility of PVA/S blend films decreases as PVA ratio increase, which can be attributed to the hydroxyl groups present in PVA [34-38]. However, inter- and intra-molecular hydrogen bonds between the hydroxyl groups of PVA and starch enhance the solubility of PVA/S blend films in water. In addition, the residual acetate groups present in the partially hydrolyzed PVA have hydrophobic character, which hinder the inter- and intra-molecular hydrogen bonding between the adjacent hydroxyl groups, leading to higher solubility of blend films in water. Similar results were obtained, as expected, in a previously reported study [39], since water solubility increases in parallel with citric acid content in the blend. Generally, solubility of a material often can be predicted based on components of interactive energy, including dispersion force (van der Waals) and acid-base components, as well as hydrogen bonding characteristics [40, 34, 35]. On another hand, the solubility of a polymer in aqueous solution is dependent on various factors such as molecular weight, temperature or addition of a co-solvent or additive [41-44].

The solubility of PVA/S blend films decreases as Mw of PVA in the blends increases as a result of the interaction between the segments of the blends. For instance, PVA $\left(31 \times 10^{3} \mathrm{~g} / \mathrm{mole}\right) / \mathrm{S}$ films containing 95 wt $\%$ of PVA (Fig. 2A) showed shortest time of solubility in water as compared to its counterpart containing the high molecular weight PVA $\left(205 \times 10^{3} \mathrm{~g} / \mathrm{mole}\right.$ ) (Fig. 2B). The blend films dipped in water at $20{ }^{\circ} \mathrm{C}$ showed longer time of solubility confirming the formation of three-dimensional crosslinks [45]. However, the blends films that dipped in water at $40{ }^{\circ} \mathrm{C}$ showed shorter time of solubility could be briefly explained by the crosslinks break when the films are heated to higher temperature [46], [47]. Furthermore, the higher the temperature, the shorter time of solubility of the film either in water or ethanol/water solution. However, the PVA/S blends had longer time of solubility in aqueous solution containing $30 \%$ alcohol as compared to that soluble in water, probably due to the more interaction between the starch and PVA in alcoholic solution than that in aqueous solution as shown in Fig. 2 C\&D.
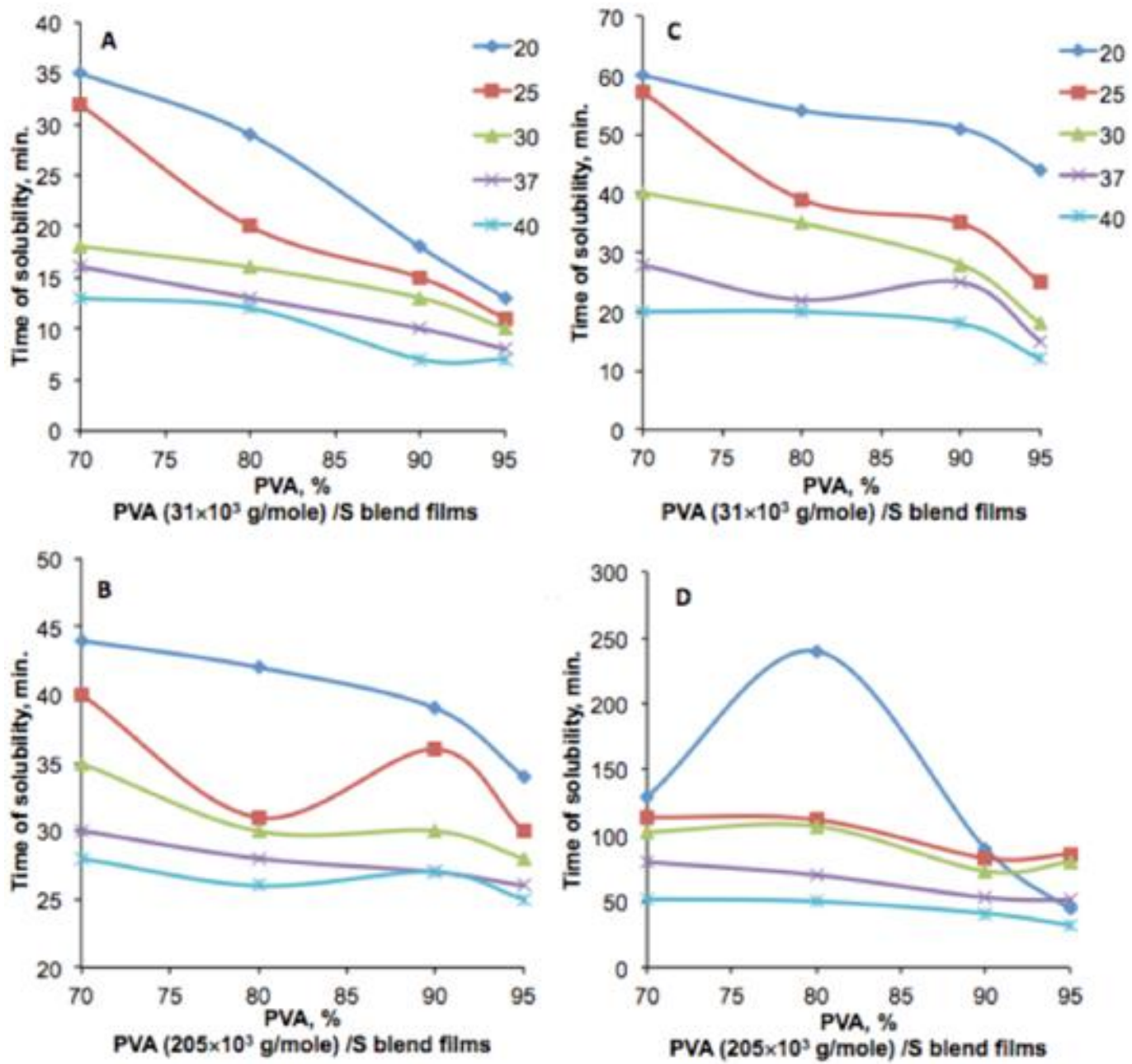

Fig. 2: Time of Solubility as a Function of PVA Content in PVA/S Blend Films at Different Temperatures in Water (A\& B); and in Water/Ethanol (70/30, V/V) Mixture (C \& D). 


\subsection{Differential scanning calorimetry (DSC)}

DSC thermograms of the PVA/S blend films with different blend ratios of (PVA \& S) and Mw of PVA (31x $10^{3} \&$ $205 \times 10^{3} \mathrm{~g} / \mathrm{mole}$ ) is shown in (Fig. $3 \mathrm{~A} \& \mathrm{~B}$ ), and a summary of the DSC features is given in Table 1 . It can be seen, there is only one $T_{g}$ in the DSC curves due the miscibility of blends. Such miscibility is attributed to the hydrogen bonding between PVA and S in the blends. The $T_{g}$ results agree well with the FT-IR data. The FT-IR data showed that the miscibility of the blends is associated with hydrogen bonding interactions between the hydroxyl groups of PVA and $\mathrm{S}$. The DSC curves in Fig. 3A shows eutectic melt between an onset of $175^{\circ} \mathrm{C}$ and midpoint of $195.5^{\circ} \mathrm{C}$ of PVA $(31 \mathrm{x}$ $\left.10^{3} \mathrm{~g} / \mathrm{mole}\right) / \mathrm{S}$ blends and an onset of $182.5^{\circ} \mathrm{C}$ and midpoint of $197.5^{\circ} \mathrm{C}$ of PVA $\left(205 \mathrm{x} 10^{3} \mathrm{~g} / \mathrm{mole}\right) / \mathrm{S}$ blend films (Fig. $3 \mathrm{~B})$. It can be observed in Table 1 that the glass transition temperature $\left(T_{g}\right)$ of PVA $\left(31 \times 10^{3} \mathrm{~g} / \mathrm{mole}\right.$ and $205 \mathrm{x} 10^{3}$ $\mathrm{g} / \mathrm{mole}$ ) was 65.80 and $64.89{ }^{\circ} \mathrm{C}$ respectively. In PVA/S blend films; $T_{g}$ was shifted to higher temperature with an increase of $\mathrm{S}$ content from $5 \%$ to $30 \%$. This is attributed to the strong interaction among hydroxyl groups on PVA and starch chains. Similar results were reported when PVA was blended with S in presence of urea [21].

It should be noted that $T_{g}$ is independent on molecular weight of PVA, $T_{g}$ of the endothermic peaks from DSC of PVA $\left(31 \times 10^{3} \mathrm{~g} / \mathrm{mole}\right) / \mathrm{S}$ blend films were found to be lower than that of PVA $\left(205 \times 10^{3} \mathrm{~g} / \mathrm{mole}\right) / \mathrm{S}$ blend films. These endothermic peaks were related to the dissolving of PVA crystals, which demonstrate solubility of blend films in water by increasing temperature.
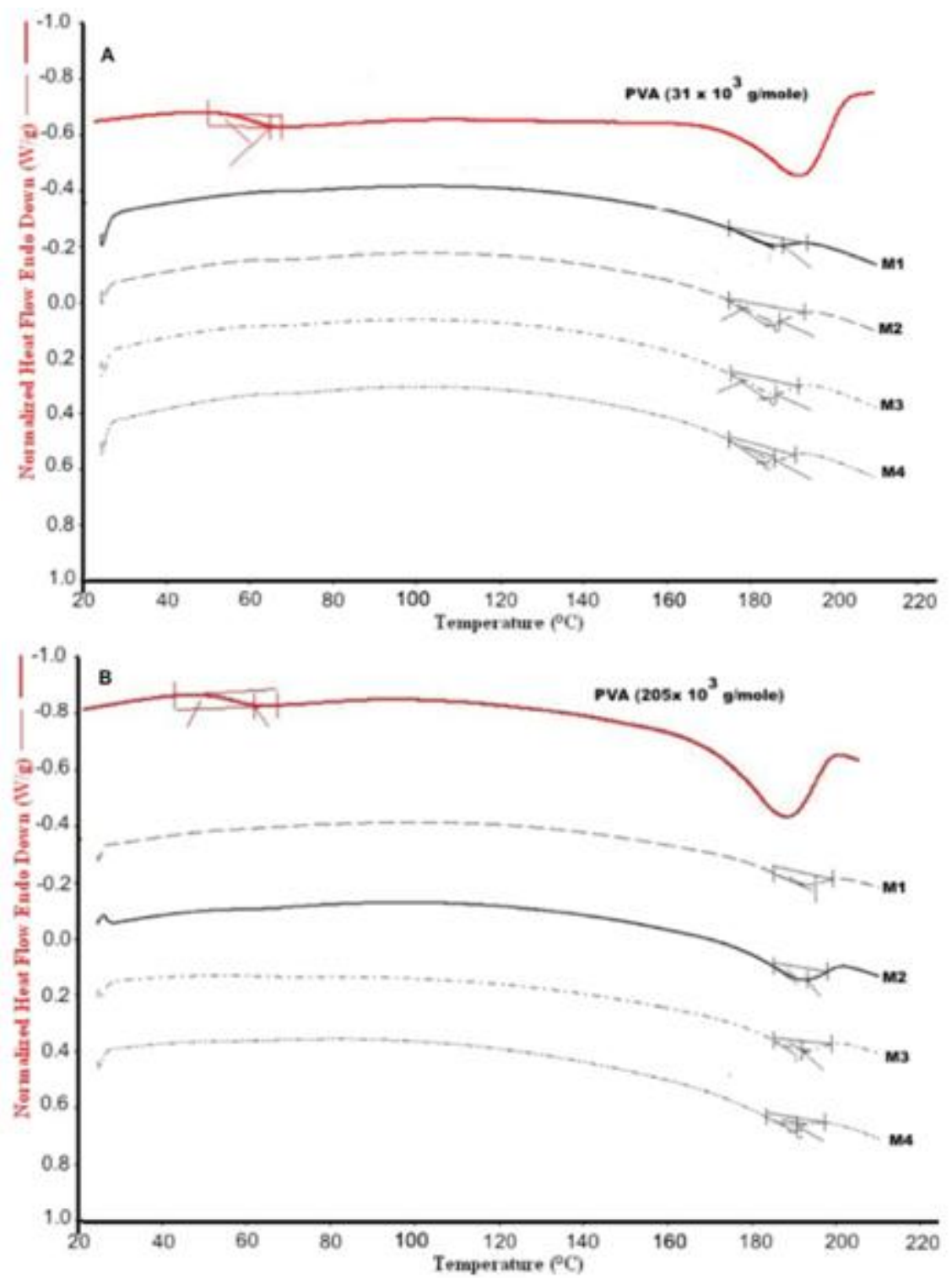

Fig. 3: DSC Thermo grams of (A) PVA $\left(31 \times 10^{3} \mathrm{G} / \mathrm{Mole}\right) / \mathrm{S}$ and (B) PVA $\left(205 \times 10^{3} \mathrm{G} / \mathrm{Mole}\right) / \mathrm{S}$ Blend Films. 


\subsection{Thermo gravimetric analysis (TGA)}

Thermal properties of the PVA/S blend films containing 70, 80, 90 and $95 \mathrm{wt} \%$ of PVA were studied by thermogravimetric analysis (TGA) and differential thermal analyses (DTA). The analyses were performed from $20^{\circ} \mathrm{C}$ to $850^{\circ} \mathrm{C}$ at $20^{\circ} \mathrm{C} / \mathrm{min}$ heating rate in air oxygen atmosphere. Fig. 4 and Table 1, summarize the TGA results of the PVA/S blend films with different molecular weight of PVA. From Fig 4, it was not observed that the variations in weight loss of pure PVA and different blend films occurred until $271{ }^{\circ} \mathrm{C}$. These results are in contrast with what is generally reported in the literature [48], [49], where the weight losses of PVA/starch blend was observed at $120{ }^{\circ} \mathrm{C}$. This can be attributed to the role of acetic acid in the cross-linking reaction between PVA and S.

Two weight losses are observed in the TGA curve as shown in Fig 4. The first weight loss (from 8.2 to $12.7 \%$ ) occurs between 271.77 and $278.72{ }^{\circ} \mathrm{C}$ for PVA $31 \times 10^{3} \mathrm{~g} / \mathrm{mole}$, and PVA $\left(31 \times 10^{3} \mathrm{~g} / \mathrm{mole}\right) / \mathrm{S}$ blend films, and (from 2.6 to11.1\%) occurs between 275 and $296.01{ }^{\circ} \mathrm{C}$ for PVA $205 \times 10^{3} \mathrm{~g} / \mathrm{mole}$ and PVA $\left(205 \times 10^{3} \mathrm{~g} / \mathrm{mole}\right) / \mathrm{S}$ blend films, which is related to the evaporation of residual moisture. The second weight loss (from 79.82 to $87.8 \%$ ) occurs between 425.05 and $432.41{ }^{\circ} \mathrm{C}$ for PVA $\left(31 \times 10^{3} \mathrm{~g} / \mathrm{mole}\right) / \mathrm{S}$ blends and (from 71.14 to $79.7 \%$ ) occurs between 420.81 and $431{ }^{\circ} \mathrm{C}$ for PVA $\left(205 \times 10^{3} \mathrm{~g} / \mathrm{mole}\right) / \mathrm{S}$ blends, which corresponds to the side chain decomposition of PVA and the main chain of the starch molecule due to broken inter- and intra-molecular hydrogen bonds between PVA and starch. The weight loss of degradation depends upon many factors such as the surrounding atmosphere, temperature and molecular weight of the polymer. For example, weight loss of PVA/S blend films decreases with increasing number average weight of PVA in the blend as shown in the Table 1. The initial decomposition temperature (IDT) corresponds to the temperature at which the initial degradation may occur [50], [12]. It was observed that IDT is higher than $306{ }^{\circ} \mathrm{C}$, which is above the highest rheological measurements employed in this study and decomposition temperature of starch [39], as shown in the Table 1. However IDT of PVA $\left(205 \times 10^{3} \mathrm{~g} / \mathrm{mole}\right) / \mathrm{S}$ blend films is higher than that of $\left(31 \times 10^{3} \mathrm{~g} / \mathrm{mole}\right) / \mathrm{S}$ blends films. On the other hand the maximum polymer degradation temperature ( $\mathrm{PDT}_{\max }$ ) corresponds to the temperature at which the maximum rate of weight loss occurred, appeared in the range from 431.7 to $444.97{ }^{\circ} \mathrm{C}$ for the PVA $\left(31 \times 10^{3} \mathrm{~g} / \mathrm{mole}^{\mathrm{e}} / \mathrm{S}\right.$ blend films and in the range from 441.01 to $450.29^{\circ} \mathrm{C}$ for PVA $\left(205 \times 10^{3} \mathrm{~g} / \mathrm{mole}\right) / \mathrm{S}$ blend films. The PDT max increases as molecular weight of the PVA increases. The PVA $\left(205 \times 10^{3} \mathrm{~g} / \mathrm{mole}\right) / \mathrm{S}$ blend films containing $80 \%$ PVA (M2) shows the highest $\mathrm{PDT}_{\max }$ at a temperature of $450{ }^{\circ} \mathrm{C}$. Consistently, thermal stability of blend film depends on the composition of the two components, molecular weight and the residual weight of blend films

\subsection{Mechanical properties}

The mechanical properties of PVA/S blend films as a function of molecular weight of PVA and its ratio in blend films were studied and shown in Fig. 5. It can be seen that tensile strength decreased and elongation increased with increasing PVA content in the blends. However, PVA $\left(31 \times 10^{3} \mathrm{~g} / \mathrm{mole}\right) / \mathrm{S}$ blend films showed the largest tensile as compared with PVA $\left(205 \times 10^{3} \mathrm{~g} / \mathrm{mole}\right) / \mathrm{S}$ blend films. This is presumably due to the increased hard segment contents and hydrogen bonding density in the blend films. While elongation at break of PVA $\left(31 \times 10^{3} \mathrm{~g} / \mathrm{mole}\right) / \mathrm{S}$ blend films is lower than that of PVA $\left(205 \times 10^{3} \mathrm{~g} / \mathrm{mole}\right) / \mathrm{S}$ blend films. It may be due to the increase in chain flexibility and phase separation of blend films containing the high molecular weight PVA. Furthermore, the incorporation of glacial acetic acid improved the mechanical properties of the blend films. Our results are opposite to those reported, where incorporating citric acid substantially reduced the tensile strength of the products developed under the conditions used [39], [19].

\subsection{Biodegradable properties of PVA/S blend films}

Biodegradation is defined as the degradation of an organic material caused by biological activity (biotic degradation), mainly by microorganisms via enzymatic action. The biodegradation of PVA/S blend films was studied by burial in soil, as shown in Fig. 6. The results showed that PVA/S blend films degradation occurs within 10 to 14 days in dry soil depending on the Mw of PVA. PVA $\left(31 \times 10^{3} \mathrm{~g} / \mathrm{mole}\right) / \mathrm{S}$ blend films showed degradation in 10 days while PVA $(205 \times$ $10^{3} \mathrm{~g} / \mathrm{mole}$ ) blend films degradation within 13-14 Days. For instance, it is obvious that biodegradation time, in dry soil, of PVA/S blend films increases by increasing the molecular weight of PVA. On the other hand, the degradation of the blend films in a moist environment is achieved within 3 days for all PVA/S blends. These results indicate that the blending of PVA with S enhance biodegradability of the polymer matrix (PVA) through degradation of starch, leaving a porous framework in the synthetic polymer that then slowly degrades. Furthermore, it is obvious that biodegradation time, in dry soil, of PVA/S blend films increases by increasing the molecular weight of PVA. Regardless the molecular weight of PVA, it is clear that the PVA content has no significant effect on the degradation time of PVA/S blend films in both types of soil. However, in moist soil the time of biodegradability of PVA/S blend films is drastically decreased, owing to the presence of water in soil which enhances the solubility of PVA/S blend leading to biodegradation in short time as shown in Fig. 6. Furthermore and regardless the molecular weight of PVA, it is clear that the PVA content has no significant effect on the degradation time of PVA/S blend films in both types of soil. 


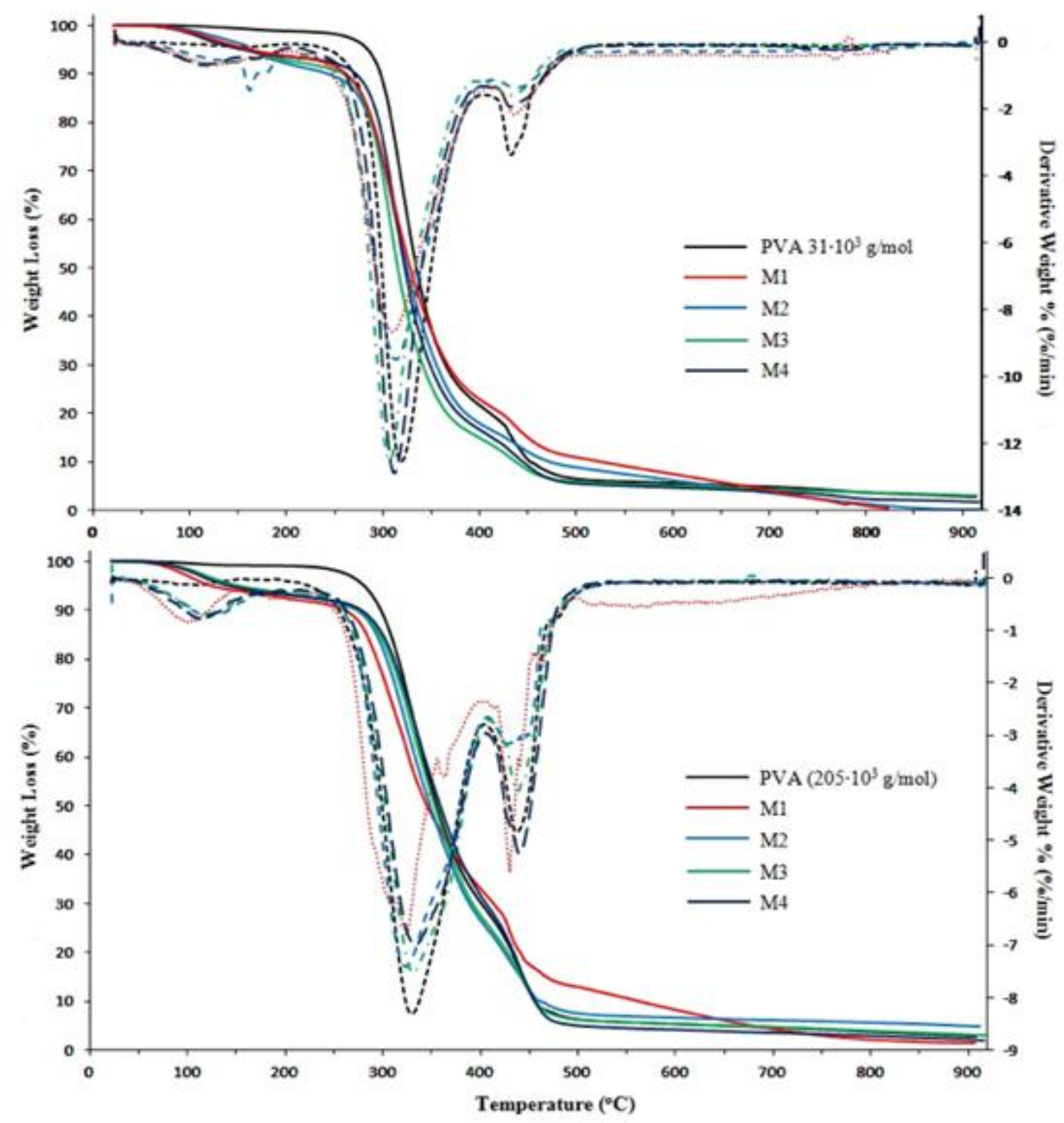

Fig. 4: TGA Curves for PVA/S Blend Films

Table 1: Thermal Properties of PVA/S Blend Films

\begin{tabular}{|c|c|c|c|c|c|c|}
\hline Sample no. & PVA: $\mathrm{S}$ blend ratio & Decomposition temperature $\left({ }^{\circ} \mathrm{C}\right)$ & Weight loss $(\%)$ & $T_{g},{ }^{\circ} \mathrm{C}^{\mathrm{a}}$ & IDT, ${ }^{\circ} \mathrm{C}^{\mathrm{b}}$ & $\mathrm{PDT}_{\max },{ }^{\circ} \mathrm{C}^{\mathrm{b}}$ \\
\hline \multicolumn{7}{|c|}{ PVA $\left(31 \times 10^{3} \mathrm{~g} / \mathrm{mole}\right) / \mathrm{S}$ blend films } \\
\hline \multirow{2}{*}{ PVA } & \multirow{2}{*}{ 100: 00} & 288.35 & 10.8 & \multirow{2}{*}{65.8} & \multirow{2}{*}{318.73} & \multirow{2}{*}{431.45} \\
\hline & & 427.39 & 83.7 & & & \\
\hline \multirow{2}{*}{ M1 } & \multirow{2}{*}{ 70: 30} & 272.61 & 10.4 & \multirow{2}{*}{187.87} & \multirow{2}{*}{309.21} & \multirow{2}{*}{436.05} \\
\hline & & 427.07 & 79.82 & & & \\
\hline \multirow{2}{*}{ M2 } & \multirow{2}{*}{ 80: 20} & 276.55 & 12.7 & \multirow{2}{*}{187} & \multirow{2}{*}{312.11} & \multirow{2}{*}{444.97} \\
\hline & & 426.08 & 84.4 & & & \\
\hline \multirow{2}{*}{ M3 } & \multirow{2}{*}{ 90: 10} & 271.77 & 9.71 & \multirow[b]{2}{*}{186.16} & \multirow[b]{2}{*}{306.19} & \multirow[b]{2}{*}{434.23} \\
\hline & & 425.05 & 87.8 & & & \\
\hline \multirow{2}{*}{ M4 } & \multirow{2}{*}{ 95: 05} & 278.72 & 8.2 & \multirow{2}{*}{185.77} & \multirow{2}{*}{311.36} & \multirow{2}{*}{431.79} \\
\hline & & 432.41 & 87.4 & & & \\
\hline \multicolumn{7}{|c|}{ PVA $\left(205 \times 10^{3} \mathrm{~g} / \mathrm{mole}\right) / \mathrm{S}$ blend films } \\
\hline \multirow{2}{*}{ PVA } & \multirow{2}{*}{ 100: 00} & 292.31 & 2.6 & \multirow{2}{*}{64.89} & \multirow{2}{*}{327.51} & \multirow{2}{*}{437} \\
\hline & & 425.87 & 76.3 & & & \\
\hline \multirow[b]{2}{*}{ M1 } & \multirow{2}{*}{ 70: 30} & 278.62 & 11.1 & & & \\
\hline & & 422.68 & 71.14 & 194.86 & 324.1 & 430.11 \\
\hline M2 & $80 \cdot 20$ & 275 & 10.6 & 103 & 32274 & 45070 \\
\hline M2 & $80: 20$ & 431 & 79.7 & 193 & 322.14 & 450.29 \\
\hline & & 292.99 & 10.37 & 10178 & $320-41$ & 73075 \\
\hline M3 & $90: 10$ & 427.66 & 78.66 & 191.78 & 330.44 & 439.15 \\
\hline$M 4$ & 05.05 & 296.01 & 10.71 & 10056 & 32037 & 44108 \\
\hline 1014 & 95:05 & 420.81 & 74.03 & 190.50 & 329.31 & 441.00 \\
\hline
\end{tabular}

a: Determined from DSC curves

b: Determined from TGA curves 


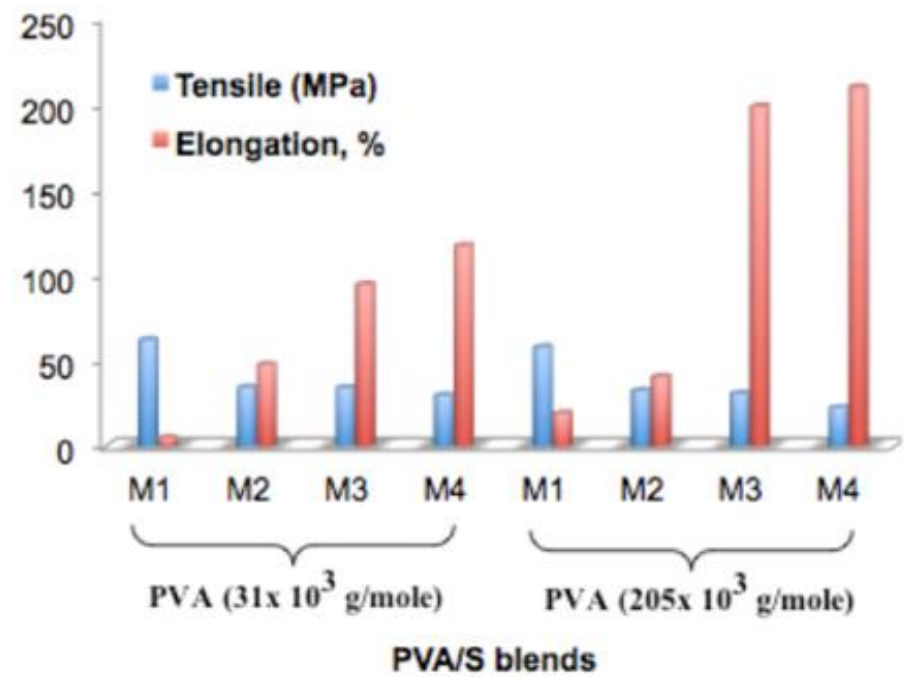

Fig. 5: Mechanical Properties of PVA/S Blend Films

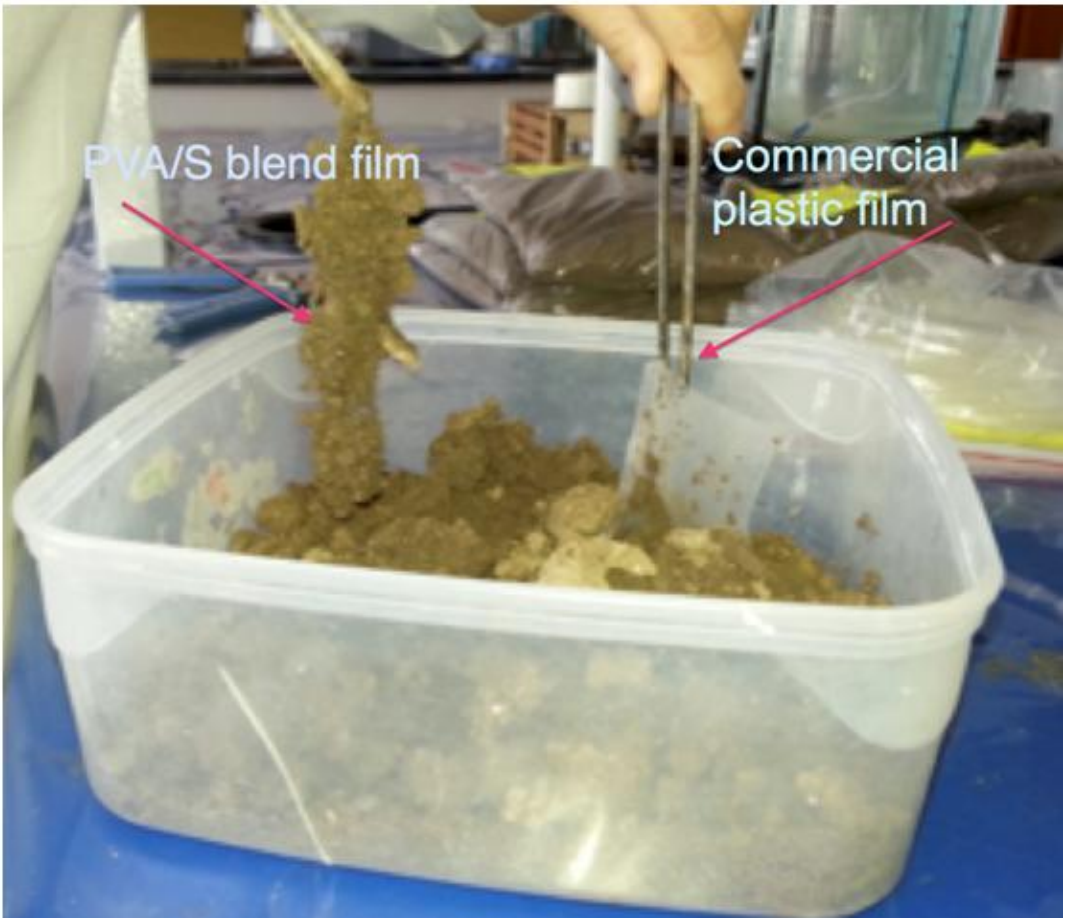

Fig. 6: Biodegradability Test of PVA/S Blend Films in Soil.

\subsection{Scanning electron microscopy (SEM)}

Fig. 7 shows SEM micrographs of pure PVA and PVA/S blend films. It can be seen that the films of pure PVA are two phases with irregular domain sizes and shapes while the films of PVA/S blends have homogeneous morphology. This means that PVA/S blends are completely miscible. This is due to the hydrophilic characteristic of the PVA that increased the hydrogen linking and the adhesion between the starch chains. As expected, and in agreement with previously reported results by authors [8], [51], [52]. However, it was seen that the size and number of the pores increases with increasing PVA ( $\left.31 \times 10^{3} \mathrm{~g} / \mathrm{mole}\right)$ content in the blend as shown in M3 and M4. This can give an indication about solubility of PVA/S films by increasing the percent of PVA in the blend from M1 to M4. 


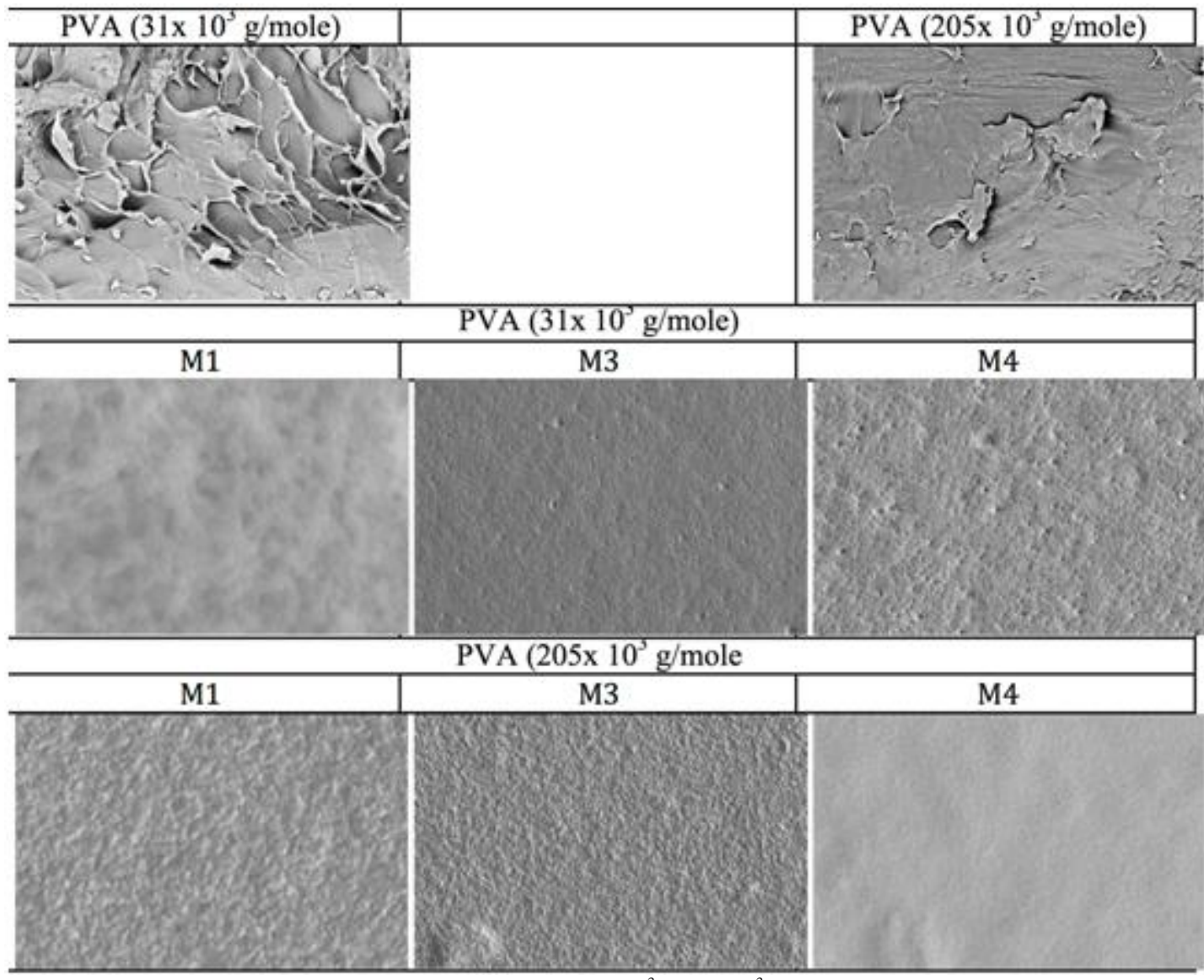

Fig. 7: Scanning Electron Micrographs of PVA $\left(31 \times 10^{3} \& 205 \times 10^{3}\right.$ G/Mole $)$ and PVA/S Blend Films

\section{Conclusion}

PVA/S blend films were prepared at different blend ratios, by using casting method, in the presence of glacial acetic acid as a crosslinking agent. Characterization of these films by FTIR, Transparency, solubility, DSC, TGA, SEM and biodegradability tests determined verified the existence of strong interactions between PVA and S molecular chains. Crosslinking agent and blend ratios were also highly effective in enhancing the physico-mechanical properties and miscibility behavior of the PVA/S blend films. DSC and SEM results confirmed the miscibility of all blend films due to hydrogen bonding interaction between PVA and starch in the blends. All the blends exhibit one $T_{g}$ which increases by increasing S from 5 to $30 \%$ in the blend. SEM images of blend films illustrate a significantly more homogeneous phase and no phase separation occurs in comparison with pure PVA. Thermogravimetric analysis results showed that IDT and $\mathrm{PDT}_{\text {max }}$ are higher than 300 and $400{ }^{\circ} \mathrm{C}$ respectively, which are above the highest rheological measurements employed in this study and decomposition temperature of starch. Solubility of the blend films in water and water/ethanol mixture increases in parallel with PVA content in blend films and temperature. More interestingly, biodegradation of PVA/S blend films in moist soil takes place rapidly (within 3 days) rather than in dry soil (10-14 days). These promising results can be exploited in using the prepared PVA/S blend films for packing applications.

\section{Acknowledgement}

The authors gratefully acknowledge the funding provided by the European Union under the Marie Curie Actioninternational incoming fellowships (FP7-PEOPLE-2011-IIF), grant agreement PIIF-GA-2011 (Project No 300427) ProSeC for research on the production of sustainable self-compacting concrete.

\section{References}

[1] Parvin, F.; Arifur Rahman, M.; Islam J.M.M.; Khan, M.A.; Saadat A.H.M., Advanced Materials Research, 123-125 (2010), 351-354. http://dx.doi.org/10.4028/www.scientific.net/AMR.123-125.351

[2] Parra, D.F.; Tadini, C.C.; Ponce, P.; Lugão, A.B., Carbohydrate Polymers, 58, (2004), 475- 481. http://dx.doi.org/10.1016/j.carbpol.2004.08.021

[3] Paul, D.R.; Barlow, J.W., Polymer, 25, 4 (1984), 487-494. http://dx.doi.org/10.1016/0032-3861(84)90207-6

[4] Negim, E.S.M.; Nurpeissova, Zh.A.; Mangazbayeva, R.A.; Khatib, J.M.; Williams, C.; Mun, G.A., Carbohydrate Polymers, 101, (2014), 415 - 422. http://dx.doi.org/10.1016/j.carbpol.2013.09.047. 
[5] He, Y.; Zhu, B.; Inoue, Y., Progress in Polymer Science, 29, (2004), 1021-1051. http://dx.doi.org/10.1016/j.progpolymsci.2004.07.002.

[6] Gordon, S.H.; Imam, S.H.; Greene, R.V., Starch-based plastics-measurement of biodegradability. In J. C. Salamone (Ed.), Boca Raton: CRC Press, Polymeric materials encyclopedia, (1996), 7885-7901.

[7] Lu, D.R.; Xiao, C.M.; Xu, S.J., eXPRESS Polymer Letters, 3, (2009), 366-375.

[8] Rahmat, A.R.; Rahman, W.A.W.A.; Lee, T.S.; Yussuf, A.A., Material Science and Engineering C, 29, 8, (2009), $2370-2377$.

[9] Zhifeng, Z., Carbohydrate Polymers, 54, (2003), 115-118. http://dx.doi.org/10.1016/S0144-8617(03)00074-2

[10] Chiellini, E.; Corti, A.; D'Antone, S.; Solaro R., Progress in Polymer Science, 28, (2003), 963-1014. http://dx.doi.org/10.1016/S0079-6700 (02)00149-1.

[11] Ramaraj, B., Polymer - Plastics Technology and Engineering, 45, 11, (2006), 1227-1231.

[12] Jianga, X.; Jiang, T.; Gana, L.; Zhanga, X.; Daia, H.; Zhang, X., Carbohydrate Polymers, 90, (2012), 1677- 1684. http://dx.doi.org/10.1016/j.carbpol.2012.07.050.

[13] Xuegang, L.; Jiwei, L.; Xiaoyan, L., Carbohydrate Polymers, 90, (2012), 1595- 1600. http://dx.doi.org/10.1016/j.carbpol.2012.07.036

[14] Lee, T.S.; Rahman, W.A.W.A.; Rahmat, A.R.; Mokhtar, M., Carbohydrate Polymers, 83, (2011), 303-305. http://dx.doi.org/10.1016/j.carbpol.2010.10.057.

[15] Jiang, Z.; Yunhai, M.; Lili, R.; Jin, T.; Ziqin, L.; Liang X., Carbohydrate Polymers, 76, (2009), 632-638. http://dx.doi.org/10.1016/j.carbpol.2008.11.028.

[16] Ziqin, L.; Yan, D.; Haitao, M.; Man, J.; Jin, T.; Jiang, Z., Carbohydrate Polymers, 89, (2012), 473- 477. http://dx.doi.org/10.1016/j.carbpol.2012.02.076.

[17] Olivato, J.B.; Grossmann, M.V.E.; Bilck, A.P.; Yamashita, F., Carbohydrate Polymers, 90, (2012), 159-164. http://dx.doi.org/10.1016/j.carbpol.2012.05.009.

[18] Olivato, J.B.; Grossmann, M.V.E.; Yamashita, F.; Eiras, D.; Pessan, L.A., Carbohydrate Polymers, 87, (2012), 2614-2618. http://dx.doi.org/10.1016/j.carbpol.2011.11.035.

[19] Yun, Y.; Na, Y.; Yoon, S., Journal of Polymers and the Environment, 14, 1, (2006), 71-78.

[20] Rui, S.; Jingliang, B.; Zizheng, Z.; Aichen, Z.; Dafu, C.; Xinhua, Z.; Liqun, Z.; Wei, T., Carbohydrate Polymers, 74, (2008), 763-770. http://dx.doi.org/10.1016/j.carbpol.2008.04.045.

[21] Luo, X.; Li, J.; Lin, X., Carbohydrate Polymers, 90, (2012), 1595- 1600. http://dx.doi.org/10.1016/j.carbpol.2012.07.036

[22] Shi, R.; Bi, J.; Zhang, Z.; Zhu, A.; Chen, D.; Zhou, X.; Zhang, L.; Tian, W., Carbohydrate Polymers, 74, (2008), 763-770. http://dx.doi.org/10.1016/j.carbpol.2008.04.045.

[23] Sin, L.T.; Rahman, W.A.W.A.; Rahmat, A.R.; Khan, M.I., Carbohydrate Polymers, 79 , (2010), $224-226$. http://dx.doi.org/10.1016/j.carbpol.2009.08.003.

[24] Negim, E.S.M.; Bahruddin, S.; Mahyuddin, R.; Idiris, M.S., J. Applied Polymer Science, 121, (2011), 8-13. http://dx.doi.org/10.1002/app.33569.

[25] Negim, E.S.M.; Bekbayeva, L.; Mun, G.A.; Zhalyrkasyn, A.A.; Idiris, M.S., World Applied Science Journal, 14, 13, (2011), 402-407.

[26] Finch, C.A., Chemical reactions and stereochemistry of polyvinyl alcohol, in: Polyvinyl alcohol, Wiley and Sons, London, (1992), p. 269.

[27] Reddy, N.; Yang, Y., Food Chemistry, (2010), 702-711. http://dx.doi.org/10.1016/j.foodchem.2009.05.050.

[28] Jayasekara, R.; Harding, I.; Bowater, I.; Christie, G.B.Y.; Lonergan, G.T., Polymer Testing, 23, (2004), 17-27. http://dx.doi.org/10.1016/S0142-9418 (03)00049-7.

[29] Xiong, H.-G.; Tang, S.-W.; Tang, H.-L.; Zou, P., Carbohydrate Polymers, 71, (2008), 263-268. http://dx.doi.org/10.1016/j.carbpol.2007.05.035.

[30] Herman, S.M.; Carolina, M.S.; Adriana, N.S.; Alexandra, A.P.M., Materials Science and Engineering: C, 28, (2008), 539-548. http://dx.doi.org/10.1016/j.msec.2007.10.088.

[31] Buléon, A.; Colonna, P.; Planchot, V.; Ball, S., Int. J. Biol. Macromol., 23, (1998), 85-112. http://dx.doi.org/10.1016/S0141-8130 (98)000403 .

[32] Blazek, J.; Gilberta, E.P., Carbohydrate Polymers, 85, (2011), 281-293. http://dx.doi.org/10.1016/j.carbpol.2011.02.041.

[33] García, M.A.; Martino, M.N.; Zaritzky, N.E., Starch/Stärke, 52, 4, (2000), 118-124.

[34] Gontard, N.; Guilbert, S.; Cuq, J.L., J. Food Sci., 58, (1993), 206-211. http://dx.doi.org/10.1111/j.1365-2621.1993.tb03246.x.

[35] Thawien, B., Songklanakarin J. Sci. Technol., 30, (2008), 149-165.

[36] Kim, C.H.; Khil, M.S.; Kim, H.Y.; Lee, H.U.; Jahng, K.Y., Journal of Biomedical Materials Research Part B: Applied Biomaterials, 78B, 2, (2006), 283-290.

[37] Vedala, H.; Huang, J.; Zhou, X.Y.; Kim, G.; Roy, S.; Choi, W.B., Applied Surface Science, 252, (2006), 7987. http://dx.doi.org/10.1016/j.apsusc.2005.10.021.

[38] Oh, S.H.; Kang, S.G.; Kim, E.S.; Cho, S.H.; Lee, J. H., Biomaterials, 24, 22, (2003), 4011.

[39] Yu, J.; Wang, N.; Ma, X., Starch/Starke, 57, (2005), 494-504. http://dx.doi.org/10.1002/star.200500423.

[40] Comyn, J., Adhesion Science. RSC Paperbacks. The Royal Society of Chemistry, Cambridge, UK, (1997).

[41] Schmaljohann, D., Advanced Drug Delivery Reviews, 58, (2006), 1655-1670. http://dx.doi.org/10.1016/j.addr.2006.09.020.

[42] Straub, M.; Gu, M., Opt. Lett., 27, (2002), 1824. http://dx.doi.org/10.1364/OL.27.001824.

[43] Shoji, S.; Sun, H.-B.; Kawata, S., Appl. Phys. Lett., 83, (2003), 608. http://dx.doi.org/10.1063/1.1595720.

[44] James, E.M., Physical Properties of Polymers Handbook, 2 edn. Springer Science Business Media, LLC, (2007).

[45] Yang, L.; Paulson, A.T, Food Res. Int., 55, (2000), 571-578. http://dx.doi.org/10.1016/S0963-9969 (00)00093-4.

[46] German, M.L.; Blumenfeld, A.L.; Guenin, Y.V.; Yuryev V.P.; Tolstoguzov, V.B., Carbohydrate Polymers, 18, 1, (1992), 27.

[47] Sun, S.F., Physical chemistry of macromolecules: basic principles and issues. Wiley, Inc. New York, (1994).

[48] Riyajan, S.-A.; Chaiponban, S.; Tanbumrung, K., Chemical Engineering Journal, 153, (2009), 199-205. http://dx.doi.org/10.1016/j.cej.2009.05.043.

[49] Hua, Y.; Wang, Q.; Tang, M., Carbohydrate Polymers, 96, (2013), 384- 388. http://dx.doi.org/10.1016/j.carbpol.2013.04.011.

[50] Holland, B.J.; Hay, J.N., Polymer, 42, (2001), 6775-6783. http://dx.doi.org/10.1016/S0032-3861 (01)00166-5.

[51] Siddaramaiah, S., Raj, B., \& Somashekar, R., Journal of Applied Polymer Science, 91, 1, (2004), 630-635. http://dx.doi.org/10.1002/app.13194.

[52] Negim, E.S.M.; Nurpeissova, Zh.A.; Mangazbayeva, R.A.; Khatib, J.M.; Williams, C.; Mun, G.A., Carbohydrate Polymers, 101, (2014), 415 - 422. http://dx.doi.org/10.1016/j.carbpol.2013.09.047 